\title{
LABORATORY EXPERIMENTS ON ENVIRONMENTAL SOURCES OF NESTMATE AND NON-NESTMATE DISCRIMINATION IN THREE SPECIES OF FORMICA ANTS (HYMENOPTERA: FORMICIDAE)
}

\author{
By Francesco Le Moli ${ }^{1}$ and Alessandra Mori ${ }^{2}$
}

\begin{abstract}
INTRODUCTION
Nestmate recognition in social insects is a central issue of sociobiological theory on kin selection (Hölldobler and Michener 1980; Gëtz 1981, 1982; Holmes and Sherman 1983), because it provides an important trait of altruistic behaviour towards kin. In fact, the ability to recognize kin from non-kin enables the individuals to achieve greater benefits by directing their altruism towards their relatives (Wilson 1975; Gadagkar 1985; Sherman and Holmes 1985; Hepper 1986; Breed and Bennett 1987). This ability is consistent with the major genetic mechanisms hypothesized for the evolution of sociality (cf. Shellman and Gamboa 1982).

In this last decade several researches have demonstrated that ants possess a great ability to discriminate between colony members (including queens) and non-colony members (Gamboa et al. 1986; Carlin and Hölldobler 1986, 1987; Bennett 1988; Keller and Passera 1989) on the basis of olfactory cues which determine the distinctive colony odour of these eusocial insects (Wilson 1971; Parry and Morgan 1979; Stuart 1987a; Obin and Vander Meer 1989). These chemical labels of kin recognition are likely surface pheromones, mainly epicuticular hydrocarbons (Howard and Blomquist 1982; Bonavita-Cougourdan et al. 1987; Blum 1987), so that alien colony odour is the main olfactory stimulus evoking attack in such insects (Jutsum 1979; Jutsum et al. 1979; Mabelis 1984; Le Moli and Mori 1986).

Generally, genetically produced (Ribbands 1965; Haskins and Haskins 1979; Mintzer 1982; Carlin and Hölldobler 1986, 1987; Mintzer and Vinson 1985) or environmentally derived factors (Lange 1960; Le Moli and Mori 1985; Obin 1986; Obin and Vander
\end{abstract}

\footnotetext{
'Istituto di Zoologia, Universita' degli Studi, Via Elce di Sotto, 06100 Perugia, Italy. 'Istituto di Zoologia, Universita' degli Studi, Viale delle Scienze, 43100 Parma, Italy. Manuscript received by the editor March 28, 1990.
} 
Meer 1988) or both (Wallis 1962; Jutsum et al. 1979; Crosland 1989) contribute to colony odour, but their relative importance may vary among different species. Other researches (Hangartner et al. 1970; Hubbard 1974) showed that in some species of ants the workers affect the odour of the soil in which they live, suggesting that odorants from the nest materials can be absorbed into the epicuticle to serve as colony odours. More recently, Stuart (1987b) demonstrated that colony segregation within local populations of polydomous colonies of Leptothorax curvispinosus is largely maintained by transient environmentally-based nestmate recognition cues.

The evident role exercised by environmental factors in determining the distinctive colony odour in some ant species, as well as the existence of early olfactory learning mechanisms in the ontogeny of nestmate and brood recognition (for a review see Jaisson 1985; Le Moli and Mori 1987; Carlin 1988), recently allowed ethologists (Jaisson 1987; Le Moli and Mori 1987) to advance a new hypothesis on fellowship (or living together) that, with the kinship hypothesis, contributes to the sociobiological theory on kin selection and inclusive fitness in such insects. More recently, in some species of ants we demonstrated (Le Moli and Mori 1989) that following the same diet, which is an important consequence of group living, is essential for the production, maintenance and evolution of the common olfactory signals on which individual recognition in these eusocial insects is based. In fact, field experiments carried out both in Formica lugubris and in Formica rufa, showed that individuals reintroduced to their natal colony after a 30-day period of laboratory housing (with nest substratum and materials) were almost always attacked by resident nestmates. This result firstly indicates that metabolic differences induced by a laboratory diet alter the distinctive colony odour in both these related species when workers are tested in the field. This implies that workers of these two Formica species constantly learn to recognize the odour of the colony, emphasizing the significance of environmental sources on ant nestmate identification. Secondly, this means that fellowship is essential to maintain the common olfactory signals of nestmate recognition and acceptance (worker-worker), since a lack of living together generally releases an overt aggression towards the reintroduced kin. 
In the present work we have attempted to confirm the abovementioned result obtained in the field, studying by a laboratory aggression test, the effect of the diet alone on nestmate recognition (homocolonial interactions) by workers of $F$. lugubris, F. rufa, and $F$. cunicularia, after a 30-day period of their maintenance in artificial colonies. Moreover, to evaluate the possible degree of aggression recorded in the homospecific tests, we analysed and quantified also the heterospecific relationships (worker-worker) of $F$. lugubris contrasted respectively with $F$. rufa and $F$. cunicularia, after a similar period of laboratory housing under artificial diet. For this heterospecific test, we considered the trials involving $F$. lugubris, because it is well known as a very efficient predatory species which shows a high level of aggression in its interspecific relationships (Le Moli and Parmigiani 1981; Le Moli et al. 1984; Le Moli and Mori 1986). Heterospecific trials were preferred to heterocolonial trials, because overt aggression is almost always recorded between such species (Le Moli et al. 1984). On the contrary, at least within wood ant species, the social conflict among heterocolonial members usually takes the form of ritualized aggression (Le Moli and Parmigiani 1982; Le Moli et al. 1982).

\section{Materials AND Methods}

\section{Natural populations}

To avoid any previous contact among members of $F$. lugubris $(\mathrm{Fl}), F$. rufa $(\mathrm{Fr})$, and $F$. cunicularia $(\mathrm{Fc})$, we selected colonies which were geographically isolated.

We used a polygynous colony of $F$. lugubris situated in the Apennine mountains (Mount Alpe), about $1200 \mathrm{~m}$ high in the province of Pavia. The anthill consisted of Larch leaves (Larix decidua) and Austrian pine needles (Pinus nigra var. austriaca).

The polygynous colony of $F$. rufa selected was located on the Prealps (Gulter Wood), at about $1100 \mathrm{~m}$ in the province of Bergamo. The materials of this anthill were mainly spruce fir (Picea excelsa) needles.

Finally, the $F$. cunicularia individuals came from a polydomous colony with multiple queens dug into the ground in the Apennine mountains (Mount Caio), at about $1200 \mathrm{~m}$ in the province of Parma. 


\section{Laboratory conditions}

Several thousand ants (workers and some homocolonial queens) with nest substratum and materials from the natural colonies were collected in the field and kept for all the experimental period in the laboratory in separate artificial nests (one for each species) made of glass $(45 \times 60 \times 30 \mathrm{~cm})$ under controlled conditions. The relative humidity was at $60-80 \%$, and the room temperature was about $22-24^{\circ} \mathrm{C}$. These artificial nests provided the ant-workers paired in the homocolonial and heterospecific interactions of the control test (see forward).

After the control test, the remaining ants were divided into 2 fragments (A, B) for each of the original colonies, and submitted for 30 days to different diets, consisting respectively of yolk, acaciahoney and water (diet $\alpha$ ) or fly tissue, eucalyptus-honey and water (diet $\beta$ ). We selected this period of time because it is probably long enough to induce metabolic differences due to the diet in workers of such colony fragments, without causing a decrease of their vigour (cf. also Le Moli and Mori 1989). According to this procedure, the ants of the three species (Fl, Fr, Fc) belonging to the fragments $A$ and $\mathrm{B}$ were fed either $\operatorname{diet} \alpha(\mathrm{FlA} \alpha, \operatorname{FrA} \alpha, \operatorname{FcA} \alpha, \operatorname{FlB} \alpha, \operatorname{FrB} \alpha$, $\mathrm{FcB} \alpha)$ or $\operatorname{diet} \beta(\mathrm{FlA} \beta, \operatorname{Fr} A \beta, \operatorname{Fc} A \beta, \operatorname{FlB} \beta, \operatorname{Fr} B \beta, \operatorname{FcB} \beta)$. Thus, we set up 12 colony fragments, 4 for each species. All the fragments of the original colonies were provided with at least one homocolonial queen, nest substratum and materials.

\section{Control test}

As a control, 48 hours after the arrival of ants in the laboratory, the homocolonial ( $\mathrm{Fl} v s \mathrm{Fl}, \mathrm{Fr} v s \mathrm{Fr}$, and $\mathrm{Fc} v s \mathrm{Fc}$ trials) and the heterospecific ( $\mathrm{Fl} v s \mathrm{Fr}, \mathrm{Fl} v s$ Fc trials) interactions of the species considered were analysed and quantified by the aggression test (see Le Moli and Mori 1986). To this purpose, workers of the three species were tested in pairs in an experimental apparatus, namely the fighting box described by Le Moli and Parmigiani (1981).

The behaviour of the dyads was observed and recorded for 15 minutes during which the following indices were measured in seconds:

- mutual investigation (MI), i.e. the time spent in reciprocal inspection;

- latency to attack (LA), i.e. the time from the first contact to the attack (when no attack occurred, 15 minute latency was allocated); 
- accumulated attacking time (AAT), i.e. the time spent in the attack/s.

The frequencies of the following elements of aggressive behaviour were also recorded: startle response, upright posture, threat with open mandibles, gaster flexing, seizing, dragging, and carrying (cf. Le Moli and Mori 1986). Startle response, upright posture and threat are patterns peculiar to a ritualized fighting mainly involved in intraspecific interactions (agonistic behaviour), whereas the other items characterize the overt aggression typical of interspecific encounters (conflict behaviour) in such species of ants (Parmigiani and Le Moli 1987). Moreover, the proportion of fighting pairs was assessed, the number of attacks delivered counted, the parts of the body attacked noted, and the number of injured and/or killed ants recorded.

After the 15-minute test, the opponents were left free to move and contact each other for a further hour and then reobserved to determine the proportion of injured and/or killed individuals by this time.

\section{Treatment test}

After the 30-day period of laboratory housing, workers belonging to the 12 fragments of the colonies were tested in pairs to analyse and quantify their intra- and interspecific interactions, using the same technique and apparatus of the controls.

Ants of the three species were tested as follows:

a) homocolonial interactions between workers of two different colony fragments fed the same laboratory diet $(\alpha$ or $\beta)$, i.e.:

- F. lugubris interactions: FlA $\alpha$ vs $\mathrm{FlB} \alpha, \mathrm{FlA} \beta$ vs $\mathrm{FlB} \beta$;

- F. rufa interactions: $\operatorname{Fr} A \alpha v s \operatorname{FrB} \alpha, \operatorname{Fr} A \beta v s \operatorname{FrB} \beta$;

- F. cunicularia interactions: $\mathrm{FcA} \alpha$ vs $\mathrm{FcB} \alpha, \mathrm{FcA} \beta$ vs $\mathrm{FcB} \beta$;

b) homocolonial interactions between workers of two different colony fragments fed a different laboratory diet $(\alpha$ or $\beta$ ), i.e.:

- F. lugubris interaction: FlA $\beta$ vs $\mathrm{FlB} \alpha$;

- F. rufa interaction: $\operatorname{Fr} A \beta$ vs $\operatorname{FrB} \alpha$;

- F. cunicularia interaction: $\mathrm{FcA} \beta$ vs $\mathrm{FcB} \alpha$;

c) heterospecific interactions of $F$. lugubris workers paired with $F$. rufa or F. cunicularia workers fed the same laboratory diet ( $\alpha$ or $\beta)$, i.e.:

- FlA $\alpha$ vs $\operatorname{FrA} \alpha, \operatorname{FlB} \beta$ vs $\operatorname{FrB} \beta, \operatorname{FlA} \beta$ vs $\operatorname{FcA} \beta, \operatorname{FlB} \alpha$ vs $\mathrm{FcB} \alpha$

d) heterospecific interactions of $F$. lugubris workers paired with 
F. rufa or $F$. cunicularia workers fed a different laboratory diet ( $\alpha$ or $\beta)$, i.e.:

- FlA $\beta$ vs $\operatorname{FrB} \alpha, \operatorname{FlB} \alpha$ vs $\operatorname{FrA} \beta, \operatorname{FlA} \beta$ vs $\operatorname{FcB} \alpha, \operatorname{FlB} \alpha$ vs $\operatorname{FcA} \beta$.

\section{RESULTS}

\section{Control test}

No attack was recorded in the encounters between homocolonial members within the three considered species (cf. interactions Fl vs $\mathrm{Fl}$, Fr $v s \mathrm{Fr}, \mathrm{Fc} v s \mathrm{Fc}$, respectively in Tables I, II, and III) after a week of laboratory housing. The paired ants performed prolonged antennal and foreleg inspections (see MI values), sometimes from an upright posture $(10 \%)$ in the Fl vs Fl trial (Table I). No sign of aggression was observed in the Fr vs Fr context (see Table II). Nevertheless, startle responses were displayed in Fc vs Fc (100\%; see Table III), and Fl vs Fl (60\%; see Table I) trials. Moreover, in this last context, threat with open mandibles occurred in $4(20 \%)$ dyads, confirming the high level of tendency to attack of this very efficient predatory species (cf. Le Moli and Parmigiani 1981; Le Moli and Mori 1986). One hour after the end of the observation period, all the ants of the three considered species were engaged in self-cleaning or exploration of the fighting box.

Concerning the heterospecific interactions, the encounters of $F$. lugubris were almost always characterized by overt attack $(95 \%$ in Fl vs Fr; $100 \%$ in Fl vs Fc trials; cf. respectively Tables IV and V). In fact, in both interspecific contexts, there was no ( $\mathrm{Fl} v s \mathrm{Fc})$ or low $(\mathrm{Fl}$ $v s$ Fr) mutual inspection, but immediate, prolonged and repeated attacks, during which $2(10 \%) \mathrm{Fl}, 2 \mathrm{Fr}$, and $3(15 \%) \mathrm{Fc}$ individuals died. Moreoever, all the elements of aggressive behaviour were shown in Fl vs Fr trial (see Table IV); whereas in the Fl vs Fc context, the items characteristic of overt combats were mainly present (see Table V). Moreover, in this last case, the combats were particularly fierce and prolonged (see AAT values), according to the higher phylogenetic relationship existing between $F$. lugubris and $F$. rufa (both belonging to the $F$. rufa group of species) than with $F$. cunicularia (Le Moli and Mori 1986). One hour after the end of the experimental period, $2(10 \%) \mathrm{Fl} v s \mathrm{Fr}$ and 1 (5\%) $\mathrm{Fl} v s \mathrm{Fc}$ dyads were still engaged in combats; moreover, $9(45 \%) F$. cunicularia were dead. 
Table I. Median (with ranges) measures and proportion of elements of aggressive behaviour for Formica lugubris homocolonial workers paired in a 15-minute laboratory test. The control test was set up after $48 \mathrm{~h}$ of laboratory conditions. The treatment test involved ants coming from colony fragment $\mathrm{A}$ or $\mathrm{B}$, and fed the same or different diet $(\alpha, \beta)$ for a 30 -day period in the laboratory.

\begin{tabular}{lcccc}
\hline & Control Test & \multicolumn{3}{c}{ Treatment Test } \\
\hline & $(1)$ & $(2)$ & $(3)$ & $(4)$ \\
& Fl $v s$ Fl & FlA $\alpha$ vs FlB $\alpha$ & FlA $\beta$ vs FlB $\beta$ & FlA $\beta$ s FlB $\alpha$ \\
\cline { 2 - 5 } Proportion & & & & \\
of fighting & $0 / 20$ & $0 / 20$ & $0 / 20$ & $3 / 20$ \\
pairs & & & & $(15 \%)$ \\
MI & 92 & 80.3 & 47.7 & 180 \\
(s) & $(20-280)$ & $(9-489)$ & $(2.3-155.4)$ & $(28.3-250.4)$ \\
LA & +900 & +900 & +900 & 900 \\
(s) & $(900-900)$ & $(900-900)$ & $(900-900)$ & $(1-900)$ \\
AAT & 0 & 0 & 0 & 0 \\
(s) & $(0-0)$ & $(0-0)$ & $(0-0)$ & $(0-19.7)$ \\
No. of & 0 & 0 & 0 & 0 \\
Attacks & $(0-0)$ & $(0-0)$ & $(0-0)$ & $(0-1)$ \\
Startle & $12 / 20$ & $3 / 20$ & $4 / 20$ & $18 / 20$ \\
Response & $(60 \%)$ & $(15 \%)$ & $(20 \%)$ & $(90 \%)$ \\
Threat & $4 / 20$ & - & $5 / 20$ & $20 / 20$ \\
& $(20 \%)$ & & $(25 \%)$ & \\
Upright & $2 / 20$ & $1 / 20$ & - & $14 / 20$ \\
Posture & $(10 \%)$ & $(5 \%)$ & & $(70 \%)$ \\
Gaster & - & - & - & $14 / 20$ \\
Flexing & & & & $(70 \%)$ \\
Seizing & - & - & - & $(15 \%)$ \\
& & & & 0 \\
\hline
\end{tabular}

MI values: (1) differs from (4) ( $\mathrm{p}<0.002)$; (1) does not differ from (2) and (3). $L A$, $A A T$, and No. of Attacks values: (1) does not differ from (2), (3), and (4).

(Two-tailed Mann-Whitney "U" test throughout)

\section{Treatment test}

When homocolonial individuals of $F$. lugubris, $F$. rufa and $F$. cunicularia coming from different colony fragments following the same laboratory diet $(\alpha$ or $\beta$ ) for 30 days, were paired in the fighting box (see interactions FlA $\alpha$ vs FlB $\alpha$, FlA $\beta$ vs FlB $\beta$ in Table I; FrA $\alpha$ vs $\operatorname{FrB} \alpha, \operatorname{Fr} A \beta$ vs $\operatorname{FrB} \beta$ in Table II; $\operatorname{FcA} \alpha$ vs $\operatorname{FcB} \alpha, \operatorname{FcA} \beta$ vs $\operatorname{FcB} \beta$ 
in Table III), they showed a behaviour not very different from that of the related control. No overt attack occurred in any case, but only quiet mutual inspection, eventually accompanied by some aggressive items, was displayed. In fact, all the elements of ritualized aggression (startle response, threat and upright posture) were generally present in FlA $\alpha$ vs $\mathrm{FlB} \alpha, \operatorname{FlA} \beta$ vs $\operatorname{FlB} \beta, \operatorname{FrA} \alpha$ vs $\operatorname{FrB} \alpha$, and $\operatorname{FrA} \beta v s \operatorname{FrB} \beta$ contexts (see Tables I and II) whereas in both FcA $\alpha$ vs $\mathrm{FcB} \beta$, and $\mathrm{FcA} \beta$ vs $\mathrm{FcB} \beta$ trials (see Table III) only startle responses occurred. The only statistically significant difference concerns the MI values in the case of the encounters involving $F$. cunicularia individuals. In fact, they were significantly less prolonged in the dyads $\mathrm{FcA} \alpha$ vs $\mathrm{FcB} \alpha$, and $\mathrm{FcA} \beta$ vs. $\mathrm{FcB} \beta$ than in the $\mathrm{Fc} v s \mathrm{Fc}$ context (cf. Table III). One hour later, concerning the interactions $\mathrm{FlA} \alpha$ vs $\mathrm{FlB} \alpha, \mathrm{FlA} \beta$ vs $\mathrm{FlB} \beta, \mathrm{FcA} \alpha$ vs $\mathrm{FcB} \alpha, \mathrm{FcA} \beta$ vs $\mathrm{FcB} \beta$, and FrA $\alpha$ vs $\operatorname{FrB} \alpha$ respectively 7 (35\%), 8 (40\%), $3(15 \%), 3$, and $2(10 \%)$ dyads were engaged in MI activity. The remaining pairs were investigating the fighting box apparatus or self-cleaning.

The behavioural response was completely different from that recorded in the related control, when homocolonial individuals of $F$. lugubris, $F$. rufa and $F$. cunicularia coming from different colony fragments were paired after a 30-day period of following a different ( $\alpha$ or $\beta$ ) laboratory diet (see interactions FlA $\beta$ vs FlB $\alpha$ in Table I; FrA $\beta$ vs $\mathrm{FrB} \alpha$ in Table II; FcA $\beta$ vs $\mathrm{FcB} \alpha$ in Table III). In fact, in 3 $(15 \%)$ of $\mathrm{FlA} \beta$ vs $\mathrm{FlB} \alpha$, and in $5(25 \%)$ of $\mathrm{FrA} \beta$ vs $\mathrm{FrB} \alpha$ trials, the two ants showed mutual attack immediately after the first contact (see LA values), but the combat was frequently interrupted by exploratory or self-cleaning behaviour (see low AAT values). Morever, in these above-cited trials the mutual investigation was not very quiet, but excited and accompanied by some elements of overt aggression (see in particular gaster flexing and seizing proportions in Tables I and II). The aggressive response was particularly evident in $\mathrm{FcA} \beta$ vs $\mathrm{FcB} \alpha$ context (Table III), where all the encounters $(100 \%)$ quickly led to overt attacks, and the combat was more prolonged (see AAT value) because of the seizing behaviour of this species. There is a statistically significant difference between the proportions of fighting pairs $(p<0.001$, Fisher exact probability test), as well as between MI, LA, AAT, and No. of attacks values in $\mathrm{FcA} \beta$ vs $\mathrm{FcB} \alpha$ compared with $\mathrm{Fc} v s \mathrm{Fc}$ (control) trials reported in Table III. In $\mathrm{FcA} \beta$ vs $\mathrm{FcB} \alpha$ interaction, contests were very vigorous, as shown by the high proportion of all the elements of overt 
Table II. Median (with ranges) measures and proportion of elements of aggressive behaviour for Formica rufa homocolonial workers paired in a 15-minute laboratory test. The control test was set up after $48 \mathrm{~h}$ of laboratory conditions. The treatment test involved ants coming from colony fragment $\mathrm{A}$ or $\mathrm{B}$, and fed the same or different $\operatorname{diet}(\alpha, \beta)$ for a 30 -day period in the laboratory.

\begin{tabular}{lcccc}
\hline & Control Test & \multicolumn{3}{c}{ Treatment Test } \\
\hline & $(5)$ & $(6)$ & $(7)$ & $(8)$ \\
& Fr $v s$ Fr & FrA $\alpha$ vs FrB $\alpha$ & FrA $\beta$ vs $\operatorname{FrB} \beta$ & FrA $\beta$ vs $\operatorname{Fr} \alpha$ \\
\cline { 2 - 5 } Proportion & & & & \\
of fighting & $0 / 20$ & $0 / 20$ & $0 / 20$ & $5 / 20$ \\
pairs & & & & $(25 \%)$ \\
MI & 161 & 142 & 117.1 & 116.6 \\
(s) & $(81-360)$ & $(33.8-323.7)$ & $(15.6-434)$ & $(38-321)$ \\
LA & +900 & +900 & +900 & +900 \\
(s) & $(900-900)$ & $(900-900)$ & $(900-900)$ & $(1-900)$ \\
AAT & 0 & 0 & 0 & 0 \\
(s) & $(0-0)$ & $(0-0)$ & $(0-0)$ & $(0-96)$ \\
No. of & 0 & 0 & 0 & 0 \\
Attacks & $(0-0)$ & $(0-0)$ & $(0-0)$ & $(0-2)$ \\
Startle & - & $5 / 20$ & $6 / 20$ & $13 / 20$ \\
Response & & $(25 \%)$ & $(30 \%)$ & $(65 \%)$ \\
Threat & - & $3 / 20$ & - & $13 / 20$ \\
& & $(15 \%)$ & & $(65 \%)$ \\
Upright & - & $3 / 20$ & $1 / 20$ & $11 / 20$ \\
Posture & & $(15 \%)$ & $(5 \%)$ & $(55 \%)$ \\
Gaster & - & - & - & $2 / 20$ \\
Flexing & & & & $(10 \%)$ \\
Seizing & - & - & - & $5 / 20$ \\
& & & & $(25 \%)$ \\
\hline
\end{tabular}

MI, LA, AAT, and No. of Attacks values: (5) does not differ from (6), (7), and (8). (Two-tailed Mann-Whitney "U" test throughout)

aggression. Particularly evident were gaster flexing (100\%) accompanied by formic acid squirting, and seizing (100\%). Sometimes, in such interaction the conflict was to the death, $2 F$. cunicularia being killed during the experimental time. One hour after the end of the experimental period, concerning the interactions FlA $\beta$ vs $\mathrm{FlB} \alpha$ and $\mathrm{FcA} \beta$ vs $\mathrm{FcB} \alpha$, respectively $1(5 \%)$ and $3(15 \%)$ dyads were still fighting; on the contrary, all the $F$. rufa individuals (interaction $\operatorname{FrA} \beta$ $v s \operatorname{Fr} \mathrm{B} \alpha$ ) were engaged in the exploration of the fighting box. Moreover, $2(5 \%) F$. cunicularia were dead, and the legs and the 
Table III. Median (with ranges) measures and proportion of elements of aggressive behaviour for Formica cunicularia homocolonial workers paired in a 15-minute laboratory test. The control test was set up after $48 \mathrm{~h}$ of laboratory conditions. The treatment test involved ants coming from colony fragment A or B, and fed the same or different diet $(\alpha, \beta)$ for a 30-day period in the laboratory.

\begin{tabular}{|c|c|c|c|c|}
\hline & Control Test & & Treatment Test & \\
\hline & $\begin{array}{c}(9) \\
\text { Fc } v s \text { Fc }\end{array}$ & $\begin{array}{c}(10) \\
F c A \alpha v s \mathrm{FcB} \alpha\end{array}$ & $\begin{array}{c}(11) \\
\operatorname{FcA} \beta v s \mathrm{FcB} \beta\end{array}$ & $\begin{array}{c}(12) \\
\operatorname{FcA} \beta v s \mathrm{FcB} \alpha\end{array}$ \\
\hline $\begin{array}{l}\text { Proportion } \\
\text { of fighting } \\
\text { pairs }\end{array}$ & $0 / 20$ & $0 / 20$ & $0 / 20$ & $20 / 20$ \\
\hline $\begin{array}{l}\text { MI } \\
\text { (s) }\end{array}$ & $\begin{array}{c}85.6 \\
(45.7-175.1)\end{array}$ & $\begin{array}{c}58.7 \\
(26.4-123.7)\end{array}$ & $\begin{array}{c}64.8 \\
(30.5-108.5)\end{array}$ & $\begin{array}{c}65.1 \\
(1-225.4)\end{array}$ \\
\hline $\begin{array}{l}\text { LA } \\
\text { (s) }\end{array}$ & $\begin{array}{c}+900 \\
(900-900)\end{array}$ & $\begin{array}{c}+900 \\
(900-900)\end{array}$ & $\begin{array}{c}+900 \\
(900-900)\end{array}$ & $\begin{array}{c}1 \\
(1-225.5)\end{array}$ \\
\hline $\begin{array}{l}\text { AAT } \\
\text { (s) }\end{array}$ & $\begin{array}{c}0 \\
(0-0)\end{array}$ & $\begin{array}{c}0 \\
(0-0)\end{array}$ & $\begin{array}{c}0 \\
(0-0)\end{array}$ & $\begin{array}{c}318.3 \\
(22.6-773.2)\end{array}$ \\
\hline $\begin{array}{l}\text { No. of } \\
\text { Attacks }\end{array}$ & $\begin{array}{c}0 \\
(0-0)\end{array}$ & $\begin{array}{c}0 \\
(0-0)\end{array}$ & $\begin{array}{c}0 \\
(0-0)\end{array}$ & $\begin{array}{c}2 \\
(1-4)\end{array}$ \\
\hline $\begin{array}{l}\text { Startle } \\
\text { Response }\end{array}$ & $20 / 20$ & $20 / 20$ & $20 / 20$ & $\begin{array}{c}3 / 20 \\
(15 \%)\end{array}$ \\
\hline Threat & - & - & - & $\begin{array}{l}15 / 20 \\
(75 \%)\end{array}$ \\
\hline $\begin{array}{l}\text { Gaster } \\
\text { Flexing }\end{array}$ & - & - & - & $20 / 20$ \\
\hline Seizing & - & - & - & $20 / 20$ \\
\hline Dragging & - & - & - & $\begin{array}{l}18 / 20 \\
(90 \%)\end{array}$ \\
\hline Carrying & - & - & - & $\begin{array}{c}6 / 20 \\
(30 \%)\end{array}$ \\
\hline $\begin{array}{l}\text { No. of } \\
\text { killing }\end{array}$ & - & - & - & $\begin{array}{l}2 / 40 \\
(5 \%)\end{array}$ \\
\hline
\end{tabular}

MI values: (9) differs from (10) ( $\mathrm{p}<0.002)$, from (11) and (12) (p<0.02). $L A, A A T$, and No. of Attacks values: (9) does not differ from (10) and (11); (9) differs from (12) $(\mathrm{p}<0.002)$.

(Two-tailed Mann-Whitney "U" test throughout) 
antennae of other $2(5 \%)$ individuals of this species were seriously injured.

As previously described (see the Methods), heterospecific encounters involved $F$. lugubris ant-workers respectively paired with $F$. rufa and $F$. cunicularia individuals.

When heterospecific members fed the same diet $(\alpha$ or $\beta$ ) for 30 days in the laboratory faced each other in the fighting box (see interactions $\operatorname{FlA} \alpha$ vs $\operatorname{FrA} \alpha, \operatorname{FlB} \beta$ vs $\operatorname{FrB} \beta$ in Table IV; FlA $\beta$ vs $\mathrm{FcA} \beta, \mathrm{FlB} \alpha$ vs $\mathrm{FcB} \alpha$ in Table $\mathrm{V}$ ), there was a significant decrease in the proportion of fighting pairs of $\mathrm{FlA} \beta$ vs $\mathrm{FcA} \beta(\mathrm{p}=0.01$, Fisher exact probability test) and $\mathrm{FlB} \alpha$ vs $\mathrm{FcB} \alpha(\mathrm{p}<0.001$, Fisher exact probability test) trials compared with Fl $v s$ Fc control (see Table V). Also in FlA $\alpha$ vs $\operatorname{Fr} A \alpha$ and $\operatorname{FlB} \beta$ vs $\operatorname{FrB} \beta$ contexts there was a decrease in the proportion of fighting pairs compared with $\mathrm{Fl} v \mathrm{Fr}$ control situation (see Table IV), but it was not statistically significant. However, in general, in such heterospecific experimental trials, the ants contacted to a significantly greater degree than the related control (see MI and LA values in Tables IV and V, respectively for interactions $\mathrm{FlA} \alpha$ vs $\mathrm{FrA} \alpha, \mathrm{FlB} \beta$ vs $\mathrm{FrB} \beta, \mathrm{Fl}$ vs $\mathrm{Fr}$; and $\mathrm{FlA} \beta$ vs $\mathrm{FcA} \beta, \mathrm{FlB} \alpha$ vs $\mathrm{FcB} \alpha, \mathrm{Fl} v s \mathrm{Fc}$ ), devoting a lesser amount of time to attack (see als ) AAT and No. of attacks values). Nevertheless, the combat caused the death of $6 F$. cunicularia (respectively $3(15 \%)$ in both interactions $\mathrm{FlA} \beta$ vs $\mathrm{FcA} \beta$ and $\mathrm{FlB} \alpha$ vs $\mathrm{FcB} \alpha$ ) during the experimental period (see No. of killing in Table V). Most of the aggressive elements were less frequent in $\operatorname{FlA} \alpha$ vs $\operatorname{FrA} \alpha$ and $\operatorname{FlB} \beta$ vs $\operatorname{FrB} \beta$ trials than in Fl vs Fr control (see Table IV), as well as in $\mathrm{FlA} \beta$ vs $\mathrm{FcA} \beta$ and $\mathrm{FlB} \alpha$ vs $\mathrm{FcB} \alpha$ trials compared with $\mathrm{Fl}$ vs Fc control context (see Table V). In both these heterospecific situations the phenomenon was particularly evident for gaster flexing and seizing behaviour. One hour after the end of the experimental time, $4(20 \%) F$. cunicularia were dead in both trials FlA $\beta$ vs FcA $\beta$ and $\mathrm{FlB} \alpha$ vs $\mathrm{FcB} \alpha$. Moreover, 5 (25\%) FlA $\alpha$ vs FrA $\alpha$ and $3(15 \%) \mathrm{FlB} \beta$ $v s \operatorname{FrB} \beta$ dyads were fighting.

Concerning the analysis of heterospecific interactions between ants fed a different laboratory diet ( $\alpha$ or $\beta$ ) for a 30-day period (cf. $\mathrm{FlA} \beta$ vs $\mathrm{FrB} \alpha, \mathrm{FlB} \alpha$ vs $\mathrm{FrA} \beta$ in Table IV; $\mathrm{FlA} \beta$ vs $\mathrm{FcB} \alpha, \mathrm{FlB} \alpha$ vs $\mathrm{FcA} \beta$ in Table $\mathrm{V}$ ), only once no fighting was recorded in a $\mathrm{FlB} \alpha$ vs $\operatorname{FrA} \beta$ pair, where the two ants investigated for an extended time (see MI value). Combats generally followed the first contact imme- 


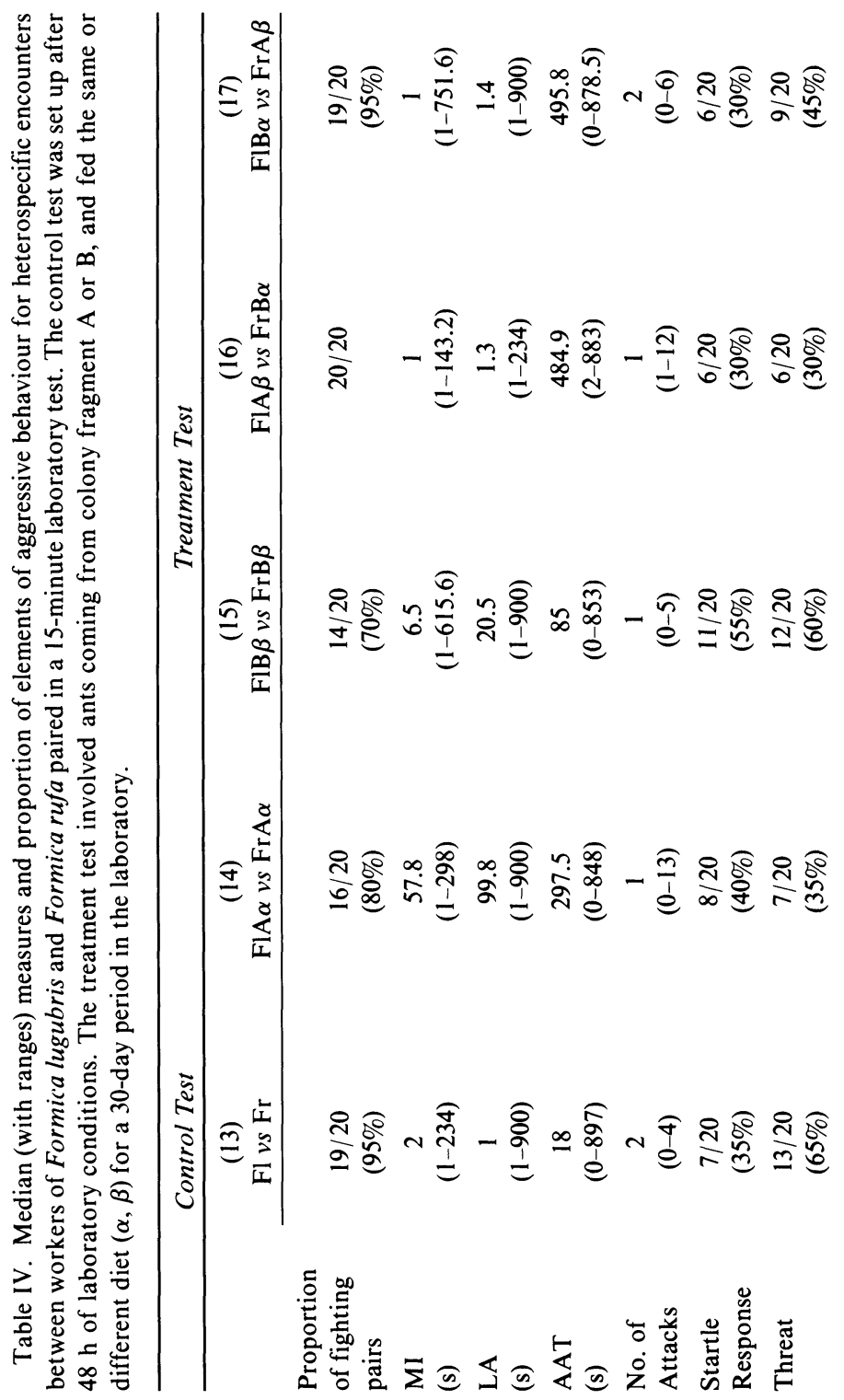




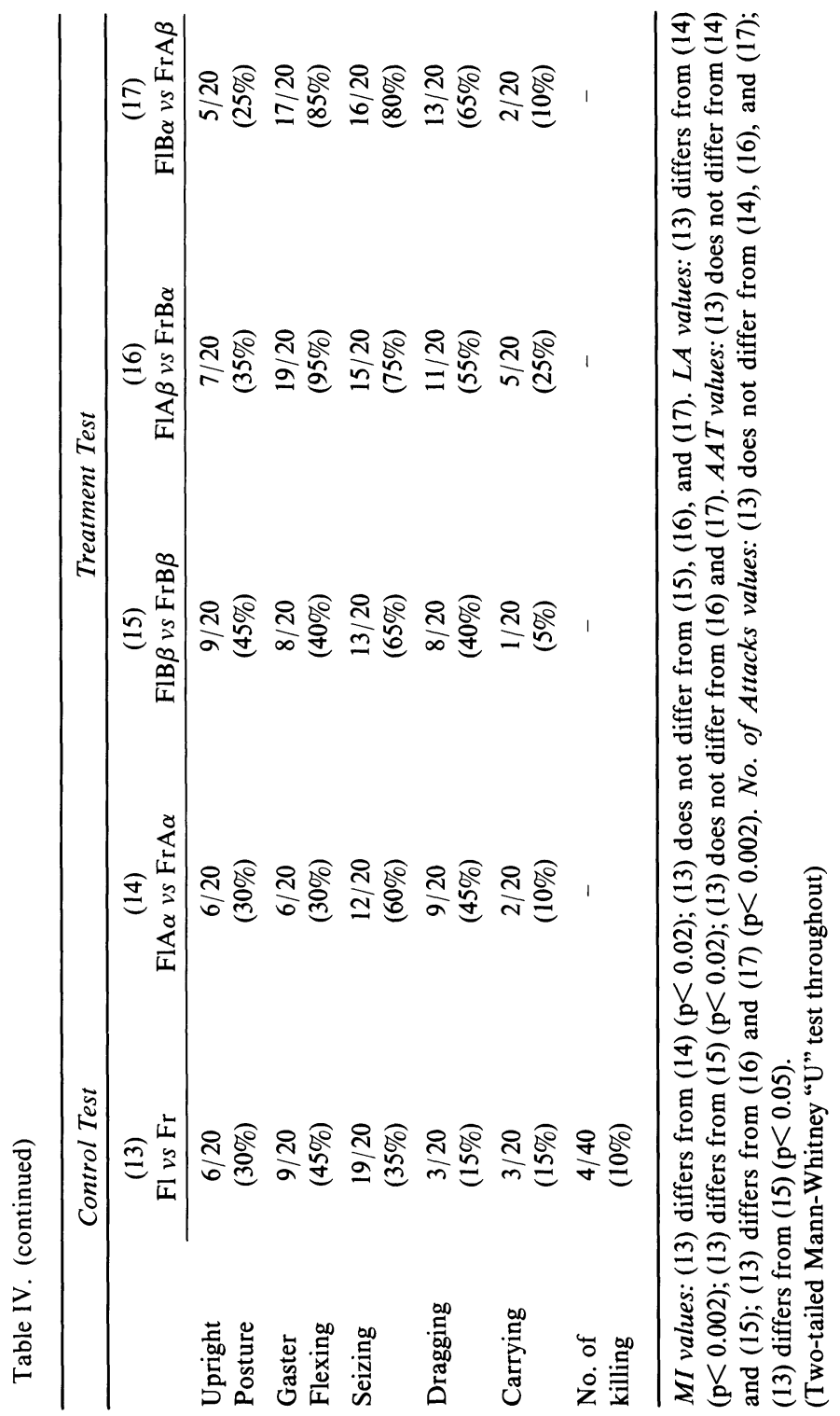


diately, producing short median LA values. Contests were very prolonged, especially in $\mathrm{FlA} \beta$ vs $\mathrm{FrB} \alpha$ and $\mathrm{FlB} \alpha$ vs $\operatorname{FrA} \beta$ encounters (see AAT values in Table IV). Moreover, the violent attacks caused the death of $7 F$. cunicularia individuals, respectively $2(10 \%)$ in FlA $\beta$ vs $\mathrm{FcB} \alpha$ and 5 (25\%) in $\mathrm{FlB} \alpha$ vs $\mathrm{FcA} \beta$ trials (see No. of killing in Table V). Finally, all the elements of aggressive behaviour were recorded in heterospecific situations, gaster flexing and seizing being the most frequent (see Tables IV and V). One hour later, $15 F$. cunicularia (respectively $8(40 \%)$ and $7(35 \%)$ in interactions FlA $\beta$ vs $\mathrm{FcB} \alpha$ and $\mathrm{FlB} \alpha$ vs $\mathrm{FcA} \beta$ ) were found dead, and 1 (5\%) FlA $\beta$ vs $\mathrm{FcB} \alpha$ dyad was still fighting. Moreover, $2 F$. rufa (respectively 1 (5\%) in both interactions $\operatorname{FlA} \beta$ vs $\operatorname{FrB} \alpha$ and $\operatorname{FlB} \alpha$ vs $\operatorname{FrA} \beta$ ) antworkers were dead one hour after the end of the experimental period, and 11 pairs (5 (25\%) in FlA $\beta$ vs $\mathrm{FrB} \alpha$ and $6(30 \%)$ in $\mathrm{FlB} \alpha$ $v s \operatorname{Fr} A \beta)$ were still engaged in fierce combats.

\section{Discussion}

Since in each colony fragment the nest materials and the substratum were the same as the original colony, and all the ants were kept under identical laboratory conditions, our results indicate that metabolic differences due to the diet alone influence the recognition cues of $F$. lugubris, $F$. rufa and $F$. cunicularia to such an extent that their species discrimination and acceptance are disturbed, particularly in F. cunicularia. This implies also that workers of these Formica species constantly learn to recognize the odour of the colony.

In fact, a certain degree of aggression characterized the homospecific relationships between workers coming from different colony fragments fed a different diet ( $\alpha$ or $\beta$ ) for a 30-day period of laboratory housing (cf. interaction FlA $\beta$ vs FlB $\alpha$ in Table I; FrA $\beta$ vs $\operatorname{FrB} \alpha$ in Table II; FcA $\beta$ vs $\mathrm{FcB} \alpha$ in Table III). Such phenomenon was more evident in $\mathrm{FcA} \beta$ vs $\mathrm{FcB} \alpha$ context, where overt attacks accompanied by all the elements of aggressive behaviour (save the upright posture) occurred in all the dyads. In this connection it is worth noting that the degree of aggression recorded in this homospecific context is similar to that recorded in the heterospecific control involving $F$. lugubris and $F$. cunicularia individuals (interaction $\mathrm{Fl}$ $v s \mathrm{Fc}$ in Table V). In fact, the differences between values of LA, $\mathrm{AAT}$, and No. of attacks in $\mathrm{FcA} \beta$ vs $\mathrm{FcB} \alpha$ and $\mathrm{Fl} v s \mathrm{Fc}$ trials are not statistically significant (Two-tailed Mann-Whitney " $U$ " test). 
Concerning the heterospecific relationships, sharing the same diet lowered the proportion of fighting pairs in both the FlA $\beta$ vs FcA $\beta$ $(70 \%)$ and $\mathrm{FlB} \alpha$ vs $\mathrm{FcB} \alpha(35 \%)$ situations compared with the $\mathrm{Fl} v s$ Fc control encounters, where fierce and violent fights were always engaged (see Table $\mathrm{V}$ ). The decrease of aggression was particularly evident in $\mathrm{FlB} \alpha$ vs $\mathrm{FcB} \alpha$ trial, where the low degree of aggression recorded was statistically comparable to the complete absence of aggression shown in the Fc vs Fc homospecific control (see Table III). In fact, the differences of LA, AAT, and No. of attacks values recorded in $\mathrm{FlB} \alpha$ vs $\mathrm{FcB} \alpha$ and in $\mathrm{Fc} v s \mathrm{Fc}$ encounters are not statistically significant (Two-tailed Mann-Whitney "U" test). Moreover, in these trials involving $F$. lugubris and $F$. cunicularia, the elements of aggressive behaviour typical of overt combat (as the gaster flexing, the seizing, the dragging and the carrying) were less frequent than in the control context, whereas the presence of items characteristic of unritualized fighting (as the upright posture) was more pronounced (see Table V). Concerning the interactions between $F$. lugubris and $F$. rufa, the decrease in the proportion of fighting pairs was less evident in FlA $\alpha$ vs $\operatorname{FrA} \alpha(80 \%)$ and $\mathrm{FlB} \beta$ vs $\operatorname{FrB} \beta(70 \%)$ trials compared with the Fl vs $\mathrm{Fr}(95 \%)$ control encounters (see Table IV), if compared with the encounters involving Fl and $\mathrm{Fc}$ fed the same laboratory diet (cf. Table V). However, also in this case, a greater tendency to pacific and prolonged mutual investigation occurred. Even if there was no sensible difference in the frequency of the items of aggression, it is worth noting that no killing was observed in both FlA $\alpha$ vs FrA $\alpha$ and FlB $\beta$ vs $\operatorname{FrB} \beta$ trials, whereas 4 individuals died during the experimental period in $\mathrm{Fl} v s$ Fr control context.

The consistent pattern of difference between $F$. cunicularia and the other two species makes our results quiet variable. However, in this connection, it is actually difficult to suggest any appropriate explanation.

As also emphasized in the InTRODUCTION, the importance of the different sources (genetically or environmentally derived) for colony odour in ants may greatly vary among species. This implies that in the course of evolution various species of these eusocial insects have developed different systems of nestmate recognition (cf. Provost 1989) and may justify the different results obtained by several studies on nestmate recognition system in different Formica ant species (e.g. Lange 1960; Wallis 1962). 


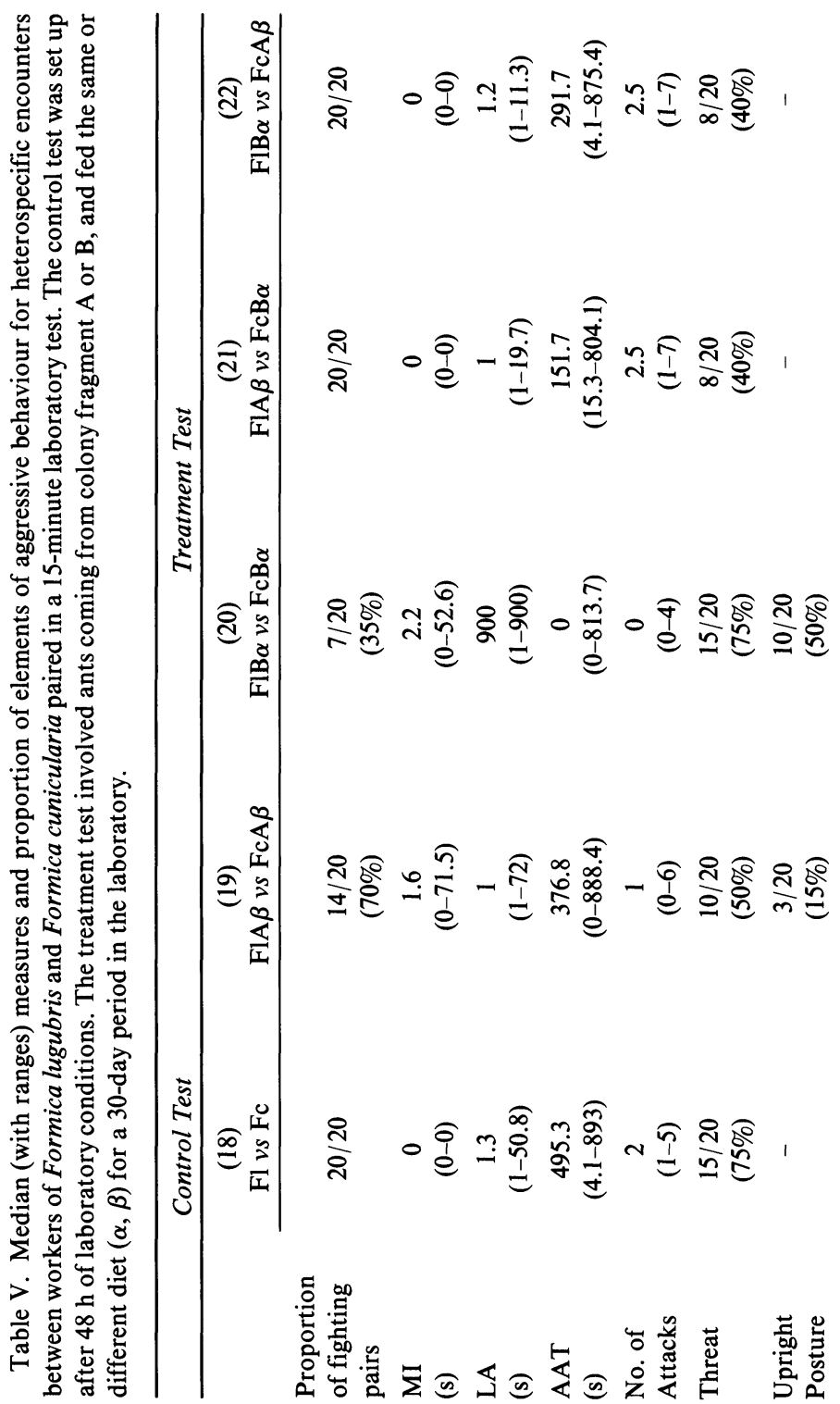




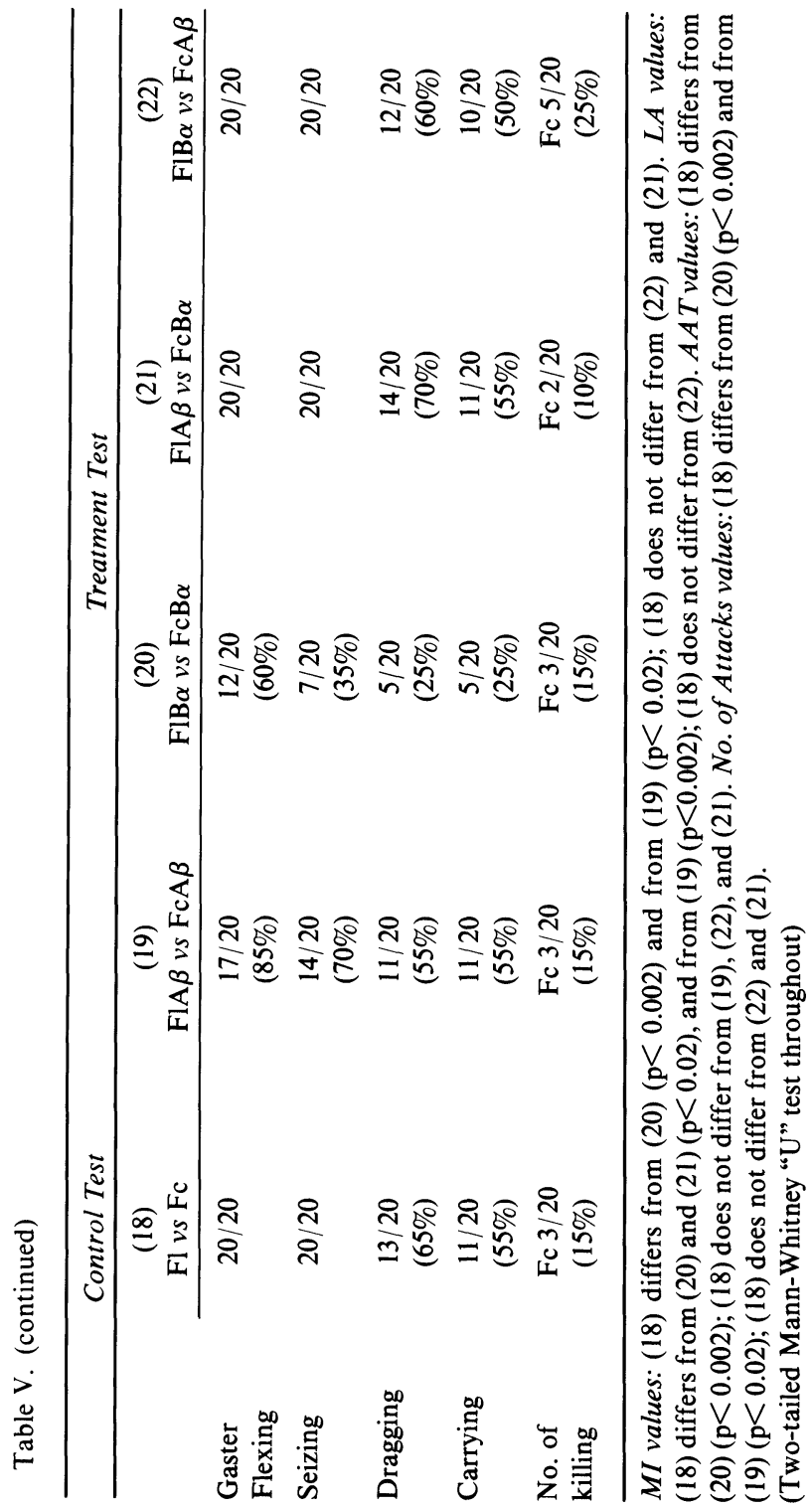


In this connection, our data sharply contrast with those obtained by Haskins and Haskins (1979) in the field which show perfect acceptance of nestmates after six months separation for Rhytidoponera metallica.

On the other hand, the present results are consistent with those recently obtained by Obin (1986) and by Obin and Vander Meer (1988) in Solenopsis invicta. In fact, also in this species, environmentally correlated cues dominate the recognition cue, and diet alone significantly modifies recognition labels and templates of laboratory-reared workers. Moreover, the influence of environmentally derived factors on nestmate recognition cues was recently observed in Leptothorax curvispinosus (Stuart 1987b).

Also in Camponotus spp. workers (Carlin and Hölldobler 1986) diet alters recognition cues, but, unlike our data, only if queenproduced information is not available, indicating that in this ant genus these chemical acquired factors are queen discriminators (cf. also Carlin and Hölldobler 1988). Moreover, the queen seems to play a crucial role in the mutual recognition processes also in other species (cf. Keller and Passera 1989; Provost 1989).

On the contrary, queen-derived cues do not appear to play a significant role in colony-level recognition in Solenopsis invicta (Obin and Vander Meer 1989). Moreover, in some ponerine ants (genus Rhytidoponera) without queen caste, the existence of a distinct colony identity reveals that workers are able to learn the spectrum of individual odours of their nestmates (Peeters 1988).

Finally, our results agree with a new sociological view (cf. Jaisson 1985, 1987; Le Moli and Mori 1987) according to which living together, or fellowship, is crucial for the development of kin recognition system. In fact, living together (and therefore also following the same diet) seems to be essential not only for the production but also for the maintenance and evolution of the common olfactory cues which are the basis of individual recognition in these eusocial insects.

\section{SUMMARY}

In this research, we tried to evaluate the influence of diet (environmental source) on intra- and interspecific interactions of three species belonging to the genus Formica (F. lugubris, F. rufa, $F$. cunicularia) and, therefore, on their nestmate and non-nestmate discrimination. 
As controls, using a pair test to measure aggression, the homocolonial and heterospecific interactions of the species studied were analysed and quantified 48 hours after their arrival in the laboratory. For each species, the remaining ants were divided into 4 experimental colony fragments, which were maintained with homocolonial queens and nest materials from natal colony, and submitted two by two to a different diet for 30 days. After this period, the homo- and heterospecific interactions of ants belonging to the experimental colony fragments were studied using the same technique of the controls.

The results suggest that metabolic differences due to diet influence the distinctive colony odour of the species tested, even if not to the same extent. In fact, diet differences enhanced aggression between former nestmates in all the species, significantly in $F$. cunicularia, but not in $F$. lugubris and $F$. rufa. On the contrary, according to the related controls, where only mutual investigation occurred, no sign of aggression was shown in homocolonial dyads involving workers coming from colony fragments submitted to the same laboratory diet. In the heterospecific trials, sharing the same diet significantly reduced aggression between $F$. lugubris and $F$. cunicularia, and lowered the proportion of fighting pairs between $F$. lugubris and $F$. rufa in comparison with the related controls.

The data obtained are discussed in relation to a new sociobiological view, according to which living together, and therefore also following the same diet, is essential for the production, maintenance and evolution of common olfactory cues on which individual recognition is based in these eusocial insects.

\section{ACKNOWLEDGEMENTS}

This research was supported in part by grants from C.N.R. and from M.P.I. (40\% and 60\%) assigned to Prof. D. Mainardi (Department of General Biology and Physiology, University of Parma) and to Prof. F. Le Moli (Institute of Zoology, University of Perugia).

We express thanks to Dr. N. Carlin, who generously improved an early draft of the manuscript with much advice and many suggestions. 


\section{REFERENCES}

BenNetT, B.

1988. Discrimination of nestmate and non-nestmate sexuals by ants (Hymenoptera: Formicidae). Insectes Soc., 35: 82-91.

BLUM, M. S.

1987. The bases and evolutionary significance of recognitive olfactory acuity in insect societies. In "From individual to collective behavior in social insects", pp. 277-293, J. M. Pasteels and J. L. Deneubourg eds. Experientia Suppl., 54. Basel: Birkhäuser Verlag, 433 pp.

Bonavita-Cougourdan, A., J. L. Clement and C. Lange

1987. Nestmate recognition: the role of cuticular hydrocarbons in the ant Camponotus vagus Scop. J. Entomol. Sci., 22: 1-10.

BREED, M. D. AND B. BENNETT

1987. Kin recognition in highly eusocial insects. In "Kin recognition in animals", pp. 243-285, D. J. C. Fletcher and C. D. Michener eds. New York: Wiley, $\mathrm{X}+465 \mathrm{pp}$.

Carlin, N. F.

1988. Species, kin and other forms of recognition in the brood discrimination behavior of ants. In "Advances in myrmecology", pp. 267-295, J. C. Trager ed, Leiden: Brill, XXVII+551 pp.

Carlin, N. F. and B. Hölldobler

1986. The kin recognition system of carpenter ants (Camponotus spp). I. Hierarchical cues in small colonies. Behav. Ecol. Sociobiol., 19: 123-134.

1987. The kin recognition system of carpenter ants (Camponotus spp.). II. Larger colonies. Behav. Ecol. Sociobiol., 20: 209-217.

1988. Influence of virgin queens on kin recognition in the carpenter ant Camponotus floridanus (Hymenoptera: Formicidae). Insectes Soc., 35: 191-197.

Crosland, M. W. J.

1989. Kin recognition in the ant Rhytidoponera confusa. I. Environmental odour. Anim. Behav., 37: 912-919.

GADAGKAR, R.

1985. Kin recognition in social insects and other animals-A review of recent findings and a consideration of their relevance for the theory of kin selection. Proc. Indian Acad. Sci. (Anim. Sci.), 94: 587-621.

Gamboa, G. J., H. K. Reeve and D. W. Pfenning

1986. The evolution and ontogeny of nestmate recognition in social wasps. Ann. Rev. Entomol., 31: 431-454.

Getz, W. M.

1981. Genetically based kin recognition systems. J. theor. Biol., 92: 209-226.

1982. An analysis of learned kin recognition in Hymenoptera. J. theor. Biol., 99: 585-597.

Hangartner, W., J. M. Reichson AND E. O. Wilson

1970. Orientation to nest material by the ant, Pogonomyrmex badius (Latreille). Anim. Behav., 18: 331-334. 
Haskins, C. P. and E. F. Haskins

1979. Worker compatibilities within and between populations of Rhytidoponera metallica. Psyche, 86: 299-312.

HEPPER, P. G.

1986. Kin recognition: functions and mechanisms. A review. Biol. Rev., 61: 63-93.

HÖlLDOBLER, B. AND C. D. MICHENER

1980. Mechanisms of identification and discrimination in social Hymenoptera. In "Evolution of social behavior: hypotheses and empirical tests", pp. 35-58, H. Markl ed. Dahlem Konferenzen. Weinheim: Verlag Chemie, $\mathrm{VI}+255 \mathrm{pp}$.

Holmes, W. G. and P. W. Sherman

1983. Kin recognition in animals. Am. Sci., 71: 46-55.

HoWARD, R. W. AND G. J. BLOMQUist

1982. Chemical ecology and biochemistry of insect hydrocarbons. Ann. Rev. Entomol., 27: 149-172.

HubBard, M. D.

1974. Influence of nest material and colony odor on digging in the ant Solenopsis invicta (Hymenoptera: Formicidae). J. Ga. Entomol. Soc., 9: $127-132$

JAISSON, P.

1985. Social behaviour. In "Comprehensive insect physiology biochemistry and pharmacology", pp. 673-694, G. A. Kerkut and L. I. Gilbert eds. Oxford: Pergamon Press, XVI+735 pp.

1987. The construction of fellowship between nestmates in social Hymenoptera. In "From individual to collective behavior in social insects", pp. 313-331, J. M. Pasteels and J. L. Deneubourg eds. Experientia Suppl., 54. Basel: Birkhäuser Verlag, 433 pp.

Jutsum, A. R.

1979. Interspecific aggression in leaf-cutting ants. Anim. Behav., 27: 833-838.

Jutsum, A. R., T. S. Saunders and J. M. Cherrett

1979. Intraspecific aggression in the leaf-cutting ant Acromyrmex octospinosus. Anim. Behav., 27: 839-844.

Keller, L. AND L. Passera

1989. Influence of the number of queens on nestmate recognition and attractiveness of queens to workers in the Argentine ant, Iridomyrmex humilis (Mayr). Anim. Behav., 37: 733-740.

LANGE, R.

1960. Über die Futterweitergabe zwischen Angehörigen verschiedener Waldameisen. Z. Tierpsychol., 17: 389-401.

Le Moli, F. AND A. Mori

1985. Environmental factors and nestmate recognition in species of the Formica rufa group. In "S.It.E. Atti, 5, Ecologia", vol. II, pp. 719-720, A. Moroni, A. Anelli \& O. Ravera eds. Atti 2nd Congr. Nat. S.It.E., Padova. Parma: Edizioni Zara, pp. 625-1248.

1986. The aggression test as a possible taxonomic tool in the Formica rufa group. Aggressive Behav., 12: 93-102. 
1987. The problem of enslaved ant species: origin and behavior. In "From individual to collective behavior in social insects", pp. 333-363, J. M. Pasteels and J. L. Deneubourg eds. Experientia Suppl., 54. Basel: Birkhäuser Verlag, $433 \mathrm{pp}$.

1989. Field experiments on environmental sources of nestmate recognition in two species of the Formica rufa group (Hymenoptera Formicidae). Ethol. Ecol. Evol., 1: 329-339.

Le Moli, F., A. Mori and S. Parmigiani

1982. Agonistic behaviour of Formica rufa L. (Hymenoptera Formicidae). Monitore zool. ital. (N.S.), 16: 325-331.

1984. Studies on interspecific aggression among red wood ant species. Formica rufa L. vs Formica lugubris Zett. (Hymenoptera Formicidae). Monitore zool. ital. (N.S.), 18: 41-51.

Le Moli, F. and S. Parmigiani

1981. Laboratory and field observations of attack by the red wood ant Formica lugubris Zett. on Formica cunicularia Latr. (Hymenoptera: Formicidae). Aggressive Behav., 7: 341-350.

1982. Intraspecific combat in the red wood ant (Formica lugubris, Zett.). Aggressive Behav., 8: 145-148.

Mabelis, A.

1984. Aggression in wood ants (Formica polyctena Foerst., Hymenoptera, Formicidae). Aggressive Behav., 10: 47-53.

MinTZer, A.

1982. Nestmate recognition and incompatibility between colonies of the acacia-ant Pseudomyrmex ferruginea. Behav. Ecol. Sociobiol., 10: 165-168.

Mintzer, A. AND S. B. Vinson

1985. Kinship and incompatibility between colonies of the acacia-ant Pseudomyrmex ferruginea. Behav. Ecol. Sociobiol., 17: 75-78.

OBIN, M. S.

1986. Nestmate recognition cues in laboratory and field colonies of Solenopsis invicta Buren (Hymenoptera: Formicidae): effect of environment and the role of cuticular hydrocarbons. J. Chem. Ecol., 12: 1965-1975.

Obin, M. S. AND R. K. Vander Meer

1988. Sources of nestmate recognition cues in the imported fire ant Solenopsis invicta Buren (Hymenoptera: Formicidae). Anim. Behav., 36: 1361-1370.

1989. Nestmate recognition in fire ants (Solenopsis invicta Buren). Do queens label workers? Ethology, 80: 255-264.

Parmigiani, S. and F. Le Moli

1987. Relationships between intra- and interspecific aggression: the case of Formica rufa group species. In "Ethological perspectives in social and presocial Arthropods”, pp. 29-32, F. Le Moli ed. Pavia: Pubbl. Ist. Entomol. Univ. Pavia, 36, 117 pp.

Parry, K. AND E. D. Morgan

1979. Pheromones of ants: a review. Physiol. Entomol., 4: 161-189. 
PeEters, C. P.

1988. Nestmate discrimination in a ponerine ant (Rhytidoponera sp. 12) without a queen caste and with a low intra-nest relatedness. Insectes Soc., 35: 34-46.

Provost, E.

1989. Social environmental factors influencing mutual recognition of individuals in the ant Leptothorax lichtensteini Bondr. (Hymenoptera: Formicidae). Behav. Processes, 18: 35-59.

RuBbands, C. R.

1965. The role of recognition of comrades in the defence of social insect communities. Symp. Zool. Soc. London, 14: 159-168.

Shellman, J. S. AND G. J. Gamboa

1982. Nestmate discrimination in social wasps: the role of exposure to nest and nestmates (Polistes fuscatus, Hymenoptera: Vespidae). Behav. Ecol. Sociobiol., 11: 51-53.

Sherman, P. W. and W. G. Holmes

1985. Kin recognition: issues and evidence. In "Experimental behavioral ecology and sociobiology", pp. 437-460, B. Hölldobler and M. Lindauer eds. Stuttgart: Fischer Verlag, XIV+488 pp.

Stuart, R. J.

1987a. Individual workers produce colony-specific nestmate recognition cues in the ant, Leptothorax curvispinosus. Anim. Behav., 35: 1062-1069.

1987b. Transient nestmate recognition cues contribute to a multicolonial population structure in the ant, Leptothorax curvispinosus. Behav. Ecol. Sociobiol., 21: 229-235.

WALLIS, D. I.

1962. Aggressive behaviour in the ant, Formica fusca. Anim. Behav., 10: 267-274.

WILSON, E. O.

1971. The insect societies. Cambridge, Mass.: Belknap Press of Harvard Univ. Press, $\mathrm{X}+548 \mathrm{pp}$.

1975. Sociobiology: the new synthesis. Cambridge, Mass.: Belknap Press of Harvard Univ. Press, IX+697 pp. 

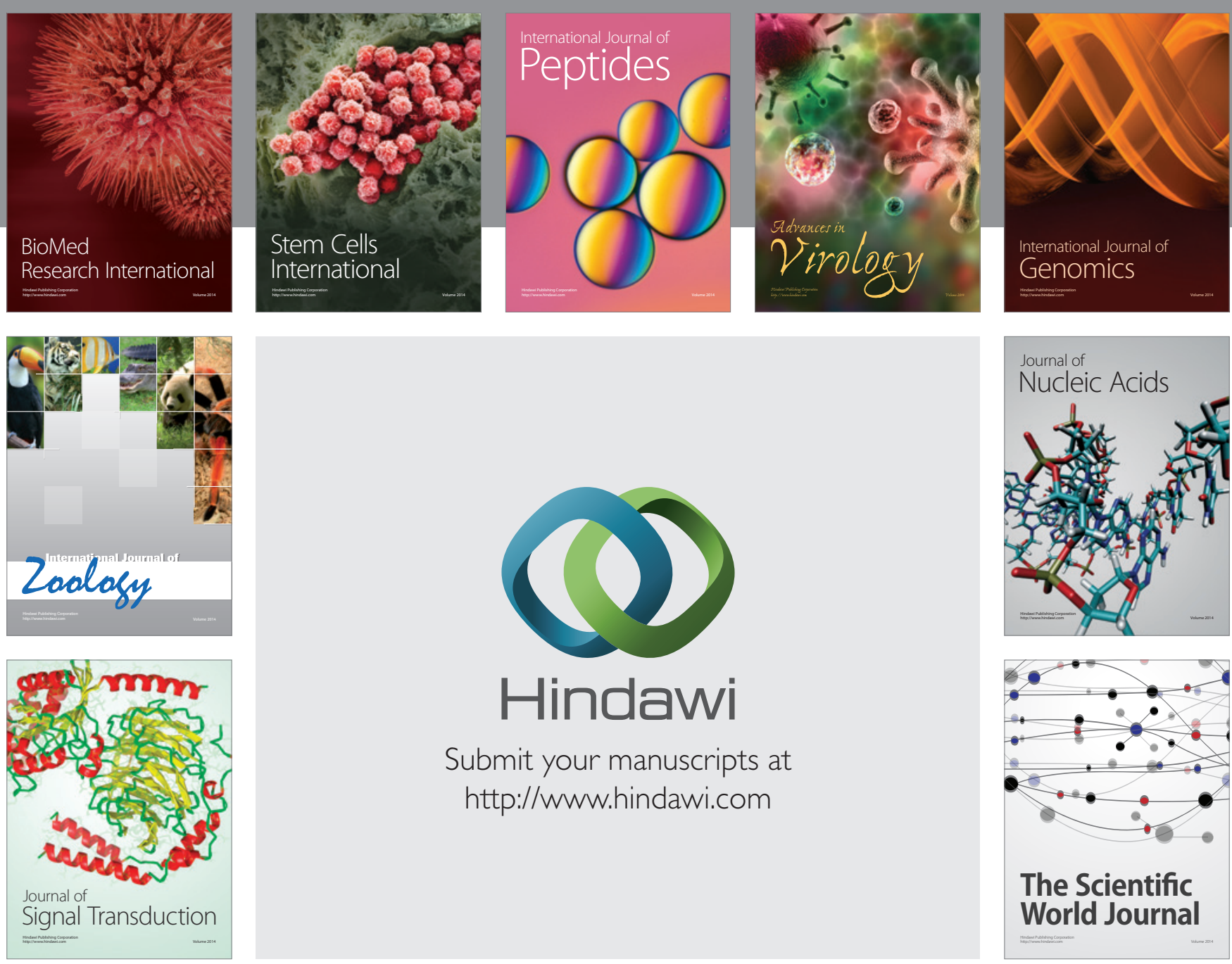

Submit your manuscripts at

http://www.hindawi.com
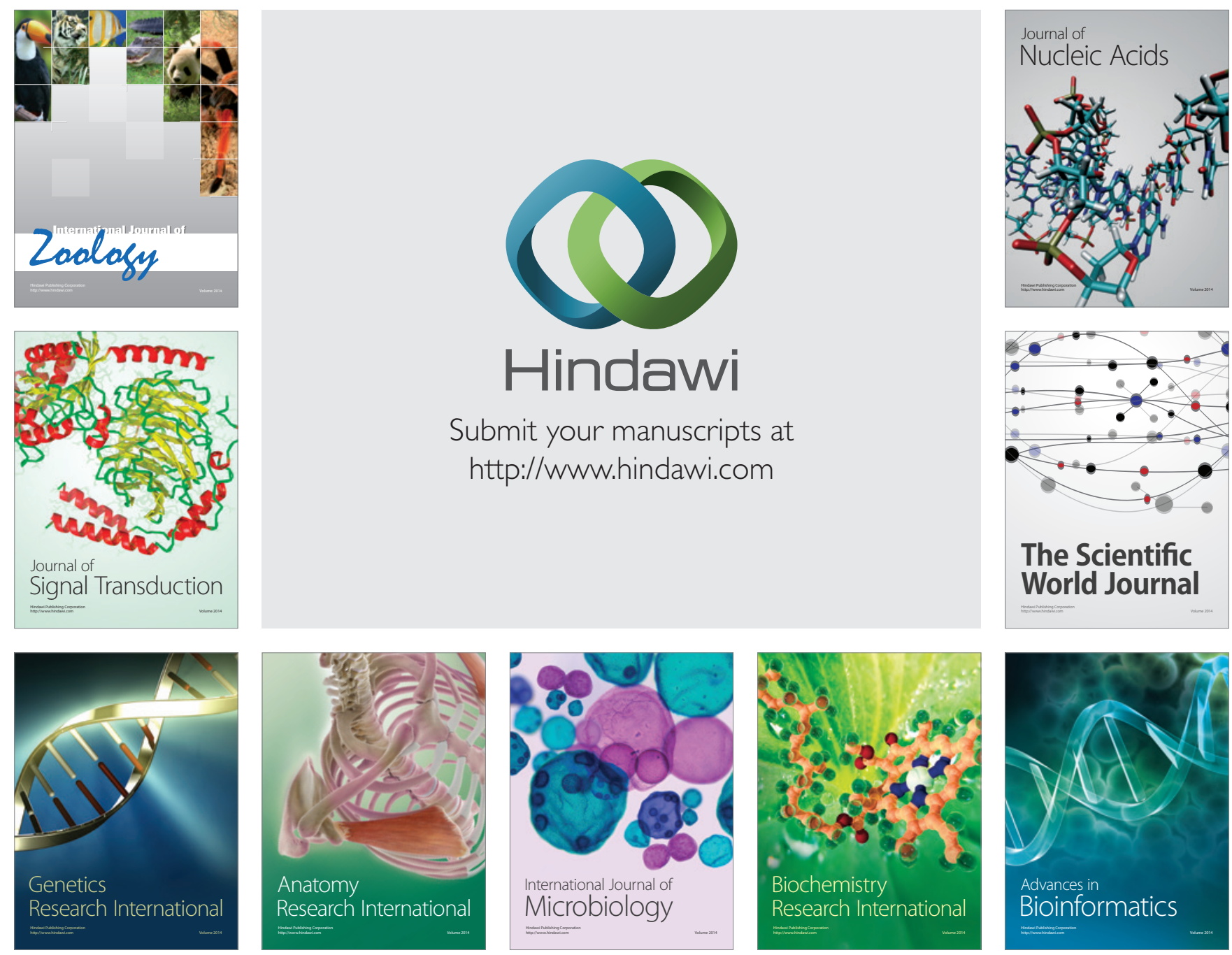

The Scientific World Journal
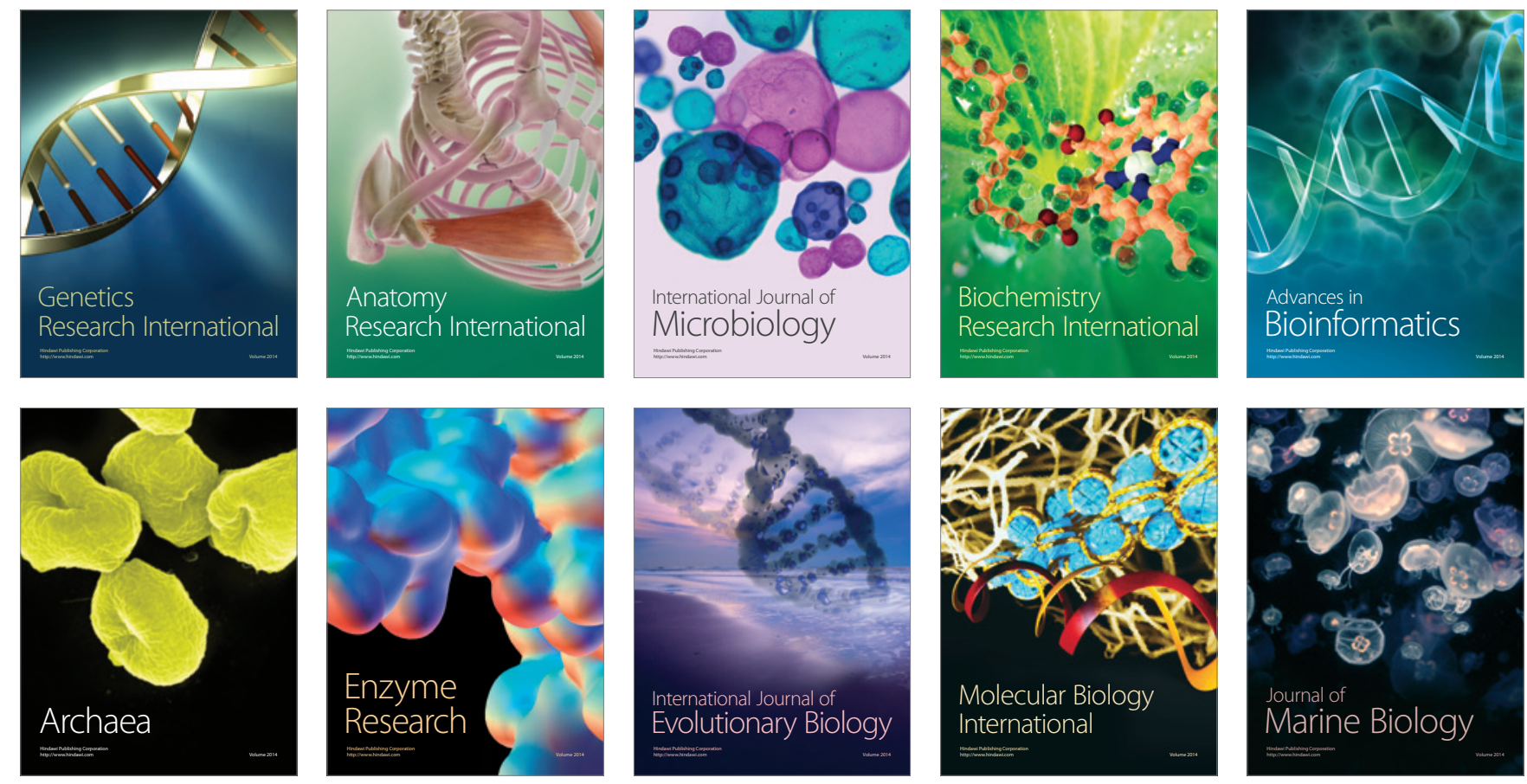